\title{
Optimize the Rolling Process Parameters for Material AA1100 using Metal Forming Simulation
}

\author{
Hemanth T. S. ${ }^{1}$ *, Y. Arunkumar ${ }^{1}$ and Srinath. M. S. ${ }^{1}$ \\ ${ }^{1}$ Affiliated to Visvesvaraya Technological University, Belagavi, Department of Industrial and \\ Production Engineering, Malnad College of Engineering, Hassan, Karnataka, India
}

\begin{abstract}
Metal forming plays a very important role in the manufacturing. Simulation of manufacturing process aids in the improvement of quality, reduce energy and resource consumption and helps in visualization of the process. The design of experiment helps in optimization of the parameters in any processes. In this paper, Taguchi optimization technique is used to predict the best results for the given inputs such as roller diameter, friction value, velocity of the rollers and percentage reduction to the forming process and get the optimized values for spread, hardness, effective stress, power required, strain rate and torque using the manufacturing simulation software. It is found that the important parameter is percentage reduction affecting the effective stress. Optimal parameters with desirability value of 0.87 have been obtained.
\end{abstract}

Keywords: Metal Rolling, DOE, AFDEX, Optimization, Aluminum

\section{Introduction}

The metal forming process is most important processing technique. One of the bulk metal forming processes is rolling where the metal is deformed by passing it through the two rollers which are rotating in opposite directions. Metals, when passed through the rolls, are reduced from initial thickness to predefined thickness. The roll gaps define the final thickness of the metal and because of the volume constancy of material after and before rolling; the reduction amount plays a major role in governing the elongation in length. There is not the only reduction in the thickness in the rolling process, but also there is a significant change in materials properties such as hardness, strength, microstructures and other properties [1]. Many research has been done in this area to improve the quality of metal rolling.

Finite element Method (FEM) is among one of the established and most widely used techniques for obtaining solutions for various complex engineering problems of many fields of engineering. Because of the advent of faster processors and high computation,

\footnotetext{
* Corresponding author: hemanththulasi@gmail.com
} 
complex engineering problems can be solved using a lesser amount of time with the greater amount of accuracy. Use of FEM in metal forming is gaining considerable attention because of the various advantages like less cost of material, a large number of trials in shorter duration and more accuracy. There are many commercially available applications to predict the deformation and other process parameters in metal forming like DEFORM 3D, ANSYS, AFDEX, FORGE, STATISTICA, FEM, Monte Carlo method and many other methods[2]-[6]. There are many factors present in the rolling process which can be simulated and optimized. The main purpose of this paper is to determine the optimal parameters that influence the quality of AA1100 alloy during the rolling process using simulation software called AFDEX. To determine the optimal parameters through individual simulations can be time-consuming. The design of experiment technique is employed to optimize the process parameter by minimum simulation runs. There are lot of research conducted to optimize the process parameters for various applications and manufacturing processes.

In rolling operation, two main changes elongation and spread occur. The main challenge here is to minimize spread. Many authors have predicted spread using either introducing new formulae or by giving modifications to experimental methods [7]. The precision of the rolled products depends on the rolling force. The rolling torque is computed using the rolling force. This rolling force is important to predict as this parameter depends on the design of the rolling mill and it is the driving force if there is any breakdown of the mill [8]. Roller speed plays a major role in determining the quality of the rolled product. There are several works done to find the effect of the rolling speed on other parameters of rolling. Strain rate, flow stress, heat of deformation, roll force and coefficient of heat transfer are all controlled by rolling speed directly. Therefore, rolling speed can be considered as one of the important parameters for rolling [9]. Strain rate is another parameter which plays a vital role in deciding the quality of roll. The strain rate can be interrelated to the speed of the roller. It can be suggested that the strain distribution is more homogeneous at high-speed rolling [10]. Shahani et al. studied the AA5083 aluminum alloy hot rolling process using simulation. The parameters such as the geometry of slab, thickness reduction, rolling speed, frictional coefficient and load are used in developing Artifical Neural Network (ANN) using the output of FE simulation by training the network. This network predicts the workpiece behavior during the rolling process [11]. In the present work, the effect of rolling parameters and optimisation of AA1100 for the billet of size $40 \mathrm{~mm} \times 40 \mathrm{~mm} \times 100 \mathrm{~mm}$ length is considered. The parameters such as stress, strain rate, torque, hardness and power required are optimised for the given input parameters reduction percentage, roller speed, roller diameter and coefficient of friction.

\section{Simulation Procedure}

The basic step for simulating any process is to define the model and the required tools for computation. In this analysis, the necessary modeling is done using the NX software which enables easy conversion of the model to any format for analysis. For the rolling process, the rollers and billet are the geometric parameter and depending on the requirement it is modeled in the NX environment. The modeled process in this analysis is then converted to .STL (Stereo lithographic format) so that it would be easy to manipulate the model in the simulation environment. In the NX environment, the required model is oriented towards $\mathrm{Y}$ axis so that when the model is imported to the simulation, the billet moves perpendicular to the $\mathrm{Y}$-axis as it happens in real-world. The software used for simulation is AFDEX (Advisor as friend for Forging Design Experts) which is a metal forming simulation 
software. The finalized CAD model is imported to simulation environment, further minor changes in the positions are made and finally all the necessary inputs parameters, properties are applied to the model for analysis. The parameters used in the simulation environment is given in Table 1. The material selected for the present analysis is AA1100 alloy. This aluminum is low strength commercial grade which is useful in pyrotechnic powder, chemical plant equipment, architectural flashing, cable sheathing and lamp reflectors. The chemical composition of available commercial AA1 100 is $\mathrm{Fe} 0.57 \%, \mathrm{Cu} 0.12 \%$, Si $0.13 \%$, Ti $0.03 \%, \mathrm{Mg}$ is $0.02 \%, \mathrm{Mn}$ is $0.013, \mathrm{Ni}$ is $0.017, \mathrm{Zn}$ is $0.01 \%$ and remaining is aluminum [12]. The mechanical property of the selected material are Modulus of Elasticity is 70-80 $\mathrm{GPa}$, Poisson's ratio is 0.33 , density is $2.71 \mathrm{~g} / \mathrm{cc}$, tensile strength is $110 \mathrm{MPa}$ and yield strength is $105 \mathrm{MPa}$ [12].

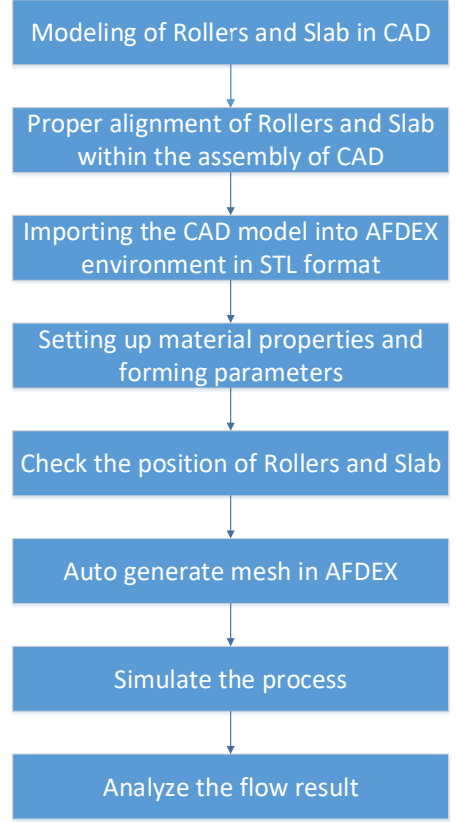

Fig. 1. Flow chart of Rolling Process Simulation

Fig. 2. Modeling of Rollers and Billet in NX

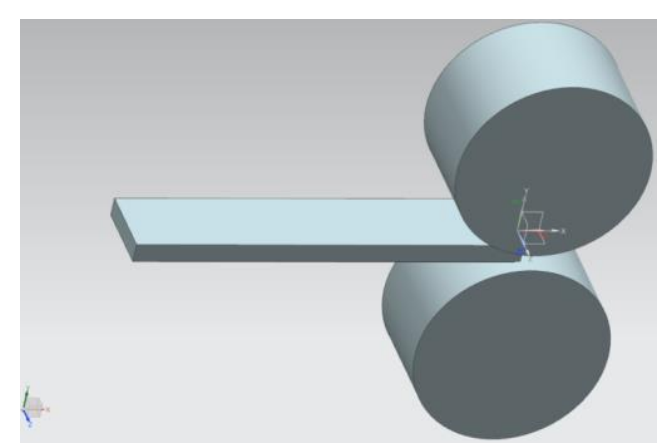


Table 1. Parameters selected from simulation

\begin{tabular}{|l|l|}
\hline Type of Forming & Cold Rolling \\
\hline Type of Simulation & 3D without flash \\
\hline Type of analysis & Flow analysis \\
\hline Deformation & Rigid Plastic \\
\hline Billet material & AA1100 \\
\hline Translation Velocity & Depends on the simulation trial \\
\hline Lubrication & Depends on the simulation trial \\
\hline
\end{tabular}

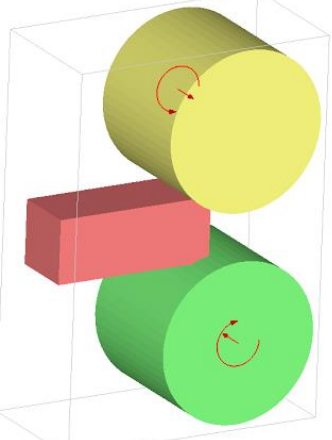

a. Before meshing

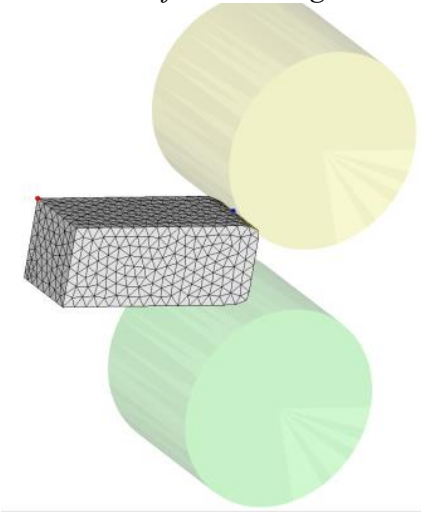

a. Before Rolling

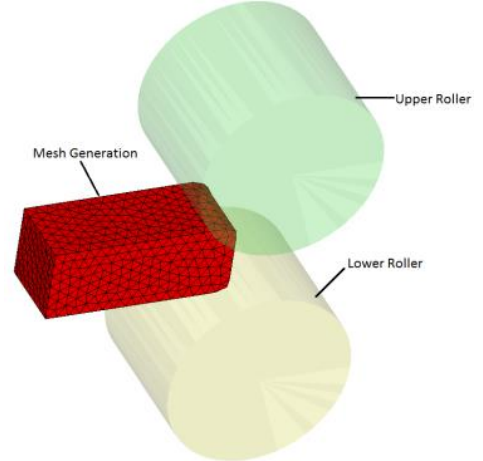

b. After meshing

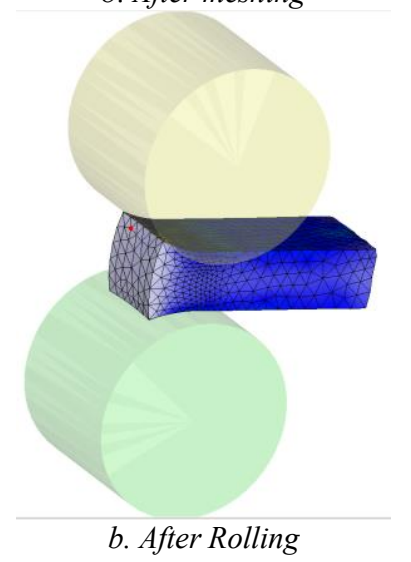

Fig. 4. Meshing before and after Rolling Process

\subsection{Plan for Simulation}

The Taguchi method is used in the present investigation; this is one of the powerful design of experiment tools available. Taguchi method is the simple, systematic and efficient approach in determining optimal forming parameters. Conventional experiment methods are costly, complex and time-consuming. Relatively many numbers of experiments needed to be carried out to study the entire process, whereas Taguchi method employs an orthogonal array for studying the process with a lesser number of experiments. The traditional experiment required experimenting by changing one parameter and keeping other parameters constant. This method fails to understand the possible interactions between parameters. It would be unlikely to understand the main effects in an experiment involving the different change in parameters. Taguchi method overcomes all these disadvantages, and it can be used for optimization of process parameters[13]. 
The steps involved in Taguchi Techniques are [14]

1. Identify the process parameters and response functions.

2. Determine the possible interactions and number of levels between the parameters.

3. Select the suitable orthogonal array.

4. Select the optimal level of process parameter through ANOVA analysis.

5. Perform the confirmation experiment for verification of optimal process parameter.

The chosen input parameters and their levels for the simulations are as shown in Table 2. For the selection of the values of the input process parameters, trial runs were made by varying one parameter and keeping other variables constant. By measuring the possible reduction without any defects and with equal intervals, the working ranges for the parameters were selected. The range and number of levels for the design parameters is as shown in Table 2. The rolling operations were performed as per the conditions governed by the design matrix developed by the Taguchi techniques.

Table 2. Parameters and their levels

\begin{tabular}{|l|c|c|c|}
\hline \multicolumn{1}{|c|}{ Parameters } & Level 1 & Level 2 & Level 3 \\
\hline Roller diameter (mm) & 100 & 200 & 300 \\
\hline Speed (RPM) & 60 & 120 & 240 \\
\hline Reduction (\%) & 25 & 30 & 40 \\
\hline Frictional Coefficient & 0.3 & 0.25 & 0.15 \\
\hline
\end{tabular}

\section{Selection of Design matrix}

For the present work, an L9 orthogonal array with four columns and nine rows is used. This array is applied for three level process parameters. Only nine experiments can be conducted to study the rolling process for this parameters. The layout of experiments need to be carried out using L9 orthogonal array is as shown in Table 3. The value 1represents level 1; value 2 represents level 2 and value 3 represents level 3 . 
Table 3. Simulation layout using L9 array

\begin{tabular}{|c|c|c|c|c|}
\hline \multirow{2}{*}{ Run } & \multicolumn{4}{l}{ Control factors and levels } \\
\cline { 2 - 5 } & $\begin{array}{l}\text { Roller } \\
\text { Diameter(mm) }\end{array}$ & Speed, RPM & Reduction \% & Friction \\
\hline 1 & 1 & 1 & 1 & 1 \\
\hline 2 & 1 & 2 & 2 & 2 \\
\hline 3 & 1 & 3 & 3 & 3 \\
\hline 4 & 2 & 1 & 2 & 3 \\
\hline 5 & 2 & 2 & 3 & 2 \\
\hline 6 & 2 & 3 & 1 & 2 \\
\hline 7 & 3 & 1 & 3 & 3 \\
\hline 8 & 3 & 2 & 1 & 1 \\
\hline 9 & 3 & 3 & 2 & \\
\hline
\end{tabular}

\section{Analysis of simulation results}

The simulation results are analyzed, to understand the main effect of the parameters, difference between different levels of the chosen parameters and effects of levels 1 on other parameters and vice versa on the out parameters. In the present work, as it is simulation only one run is performed for all the nine sets of the experiment. Some of the output parameters are given higher importance than other parameters as they play important role in quality. The parameters such as effective stress, spread, hardness are givens higher preference than power and torque. For optimization, effective stress, spread, power and torque should be minimum whereas hardness and strain should be more. The objective of this work is to obtain the optimal value for the given set of the parameter with a minimum number of trials to save the time. However, while conducting the actual experiment using this parameters and levels are performed using the Taguchi analysis through the design expert software. The values of each trial were taken by selecting the average at six different points and for all the trails, the values were taken from the same region that is at the lower die middle region. The results from the simulation for the L9 orthogonal array is as given in Table 4.

Table 4. L9 generated Orthogonal array with results obtained from AFDEX

\begin{tabular}{|r|r|r|r|r|r|r|r|r|r|r|}
\hline Exp.No. & $\begin{array}{l}\text { Roller } \\
\text { diameter } \\
(\mathbf{m m})\end{array}$ & \multicolumn{1}{|l|}{$\begin{array}{l}\text { Speed } \\
(\mathbf{r p m})\end{array}$} & $\begin{array}{l}\text { Reductio } \\
\mathbf{n} \%\end{array}$ & $\begin{array}{l}\text { Coefficie } \\
\text { nt of } \\
\text { Friction }\end{array}$ & $\begin{array}{l}\text { Effective } \\
\text { Stress } \\
\left(\mathbf{N} / \mathbf{m m}^{2}\right)\end{array}$ & $\begin{array}{l}\text { Spread } \\
(\mathbf{m m})\end{array}$ & $\begin{array}{l}\text { Hard- } \\
\text { ness } \\
(\mathbf{B H N})\end{array}$ & $\begin{array}{l}\text { Strain } \\
\text { Rate }\end{array}$ & $\begin{array}{l}\text { Power,( } \\
\text { Watt) }\end{array}$ & $\begin{array}{l}\text { Torque( } \\
\text { N-m) }\end{array}$ \\
\hline 1 & 100 & 60 & 25 & 0.3 & 32.42 & 4.66 & 229.5 & 79.69 & 0.2017 & 0.0305 \\
\hline 2 & 100 & 120 & 30 & 0.25 & 34.3 & 5.23 & 235.5 & 86.49 & 0.3838 & 0.0283 \\
\hline 3 & 100 & 240 & 40 & 0.15 & 38.27 & 7.94 & 245.6 & 108.3 & 0.32 & 0.0165 \\
\hline 4 & 200 & 60 & 30 & 0.15 & 36.66 & 8.09 & 249.4 & 76.15 & 0.394 & 0.0622 \\
\hline 5 & 200 & 120 & 40 & 0.3 & 57.73 & 8.3 & 252.4 & 119.9 & 1.143 & 0.0914 \\
\hline 6 & 200 & 240 & 25 & 0.25 & 72.34 & 8.48 & 253.4 & 120 & 0.2477 & 0.0985 \\
\hline 7 & 300 & 60 & 40 & 0.25 & 66.11 & 7.07 & 251.1 & 121 & 0.898 & 0.0936 \\
\hline 8 & 300 & 120 & 25 & 0.15 & 56.41 & 4.57 & 192.8 & 124 & 1.13 & 0.0891 \\
\hline 9 & 300 & 240 & 30 & 0.3 & 60.37 & 4.82 & 215.5 & 140 & 0.3362 & 0.0933 \\
\hline
\end{tabular}


The obtained Desirability is 0.87 for these set of experiments which is within the acceptable limit. The optimized value obtained is as shown in Table 5.

\section{$\therefore$ Roller Diameter (mm) B: Speed (RPM) C: Reduction (\%) D: Friction}

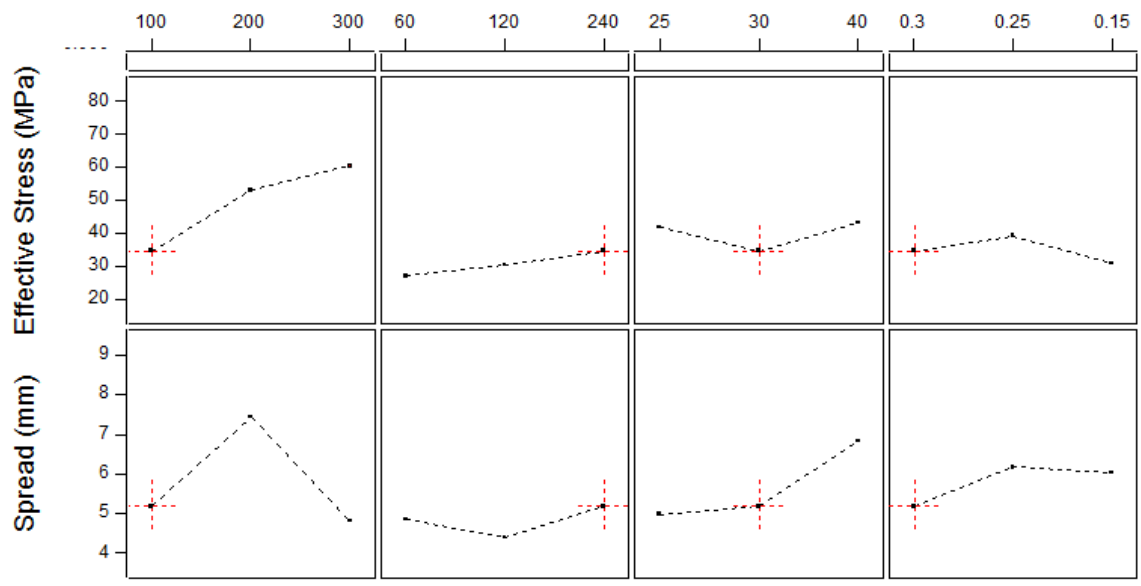

Fig. 5. Graph between Effective stress and Spread vs. the input parameters

From the Fig. 5, it can be seen that the Effective stress increases with increase in Roller diameter and speed but it decreases and increases with reduction values. Effective stress is increased and again decreased to the lowest point in case of decreased friction. Therefore, speed and Roller diameter are the important factors. Spread should be minimized and under control, from the Fig. 5 it can be observed that reduction plays a vital role for spread.

\section{$\therefore$ Roller Diameter (mm) B: Speed (RPM) C: Reduction (\%) D: Friction}

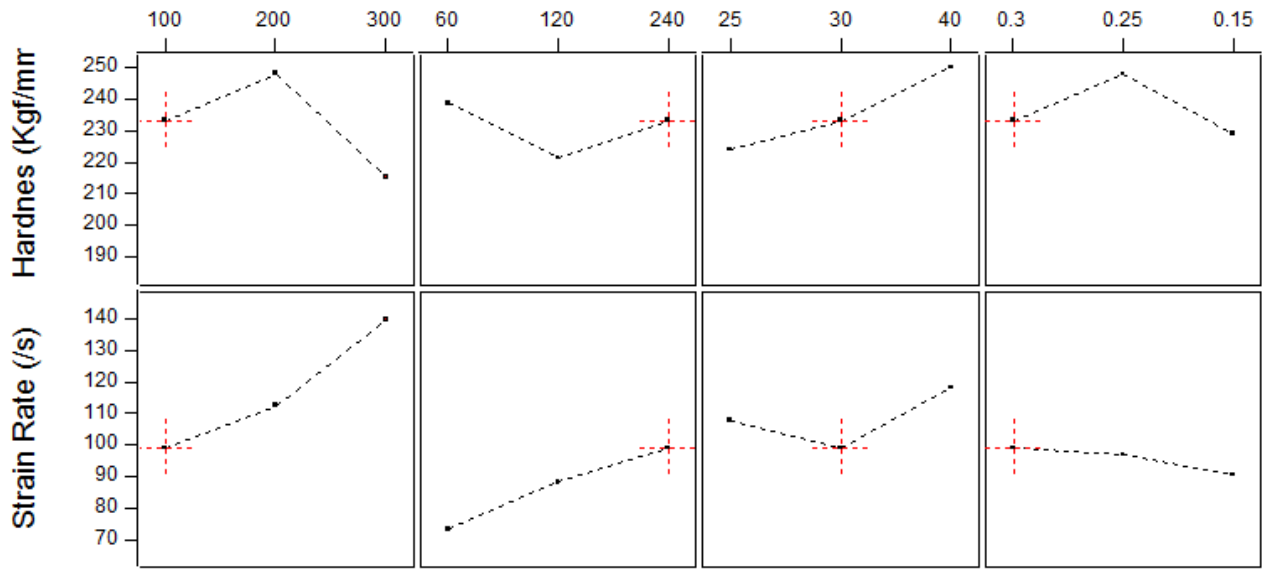

Fig. 6. Graph between Hardness and Strain Rate vs. the input parameters 
From Fig. 6, it can be seen that the reduction plays an important role in the hardness and maximum hardness can be obtained by increasing the reduction and minimum hardness can be obtained by increasing the roller diameter. Strain rate is directly proportional to the Roller diameter, speed and the friction but higher strain rates are found with increased Roller diameter.

Similarly, the power and torque relation with the input variables has been shown in Fig. 7. Both power and torque have same response concerning the input responses. There is an increase in both power and torque with an increase in Roller diameter. These responses are computed using the design of experiment software to find the optimal values for the output. There was 23 output were given by the software but the optimal values for the given input are obtained as shown in Table 5 with the desirability value was found to be 0.87 for the given value.

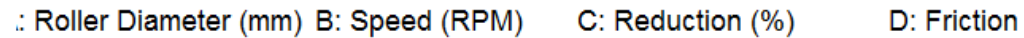

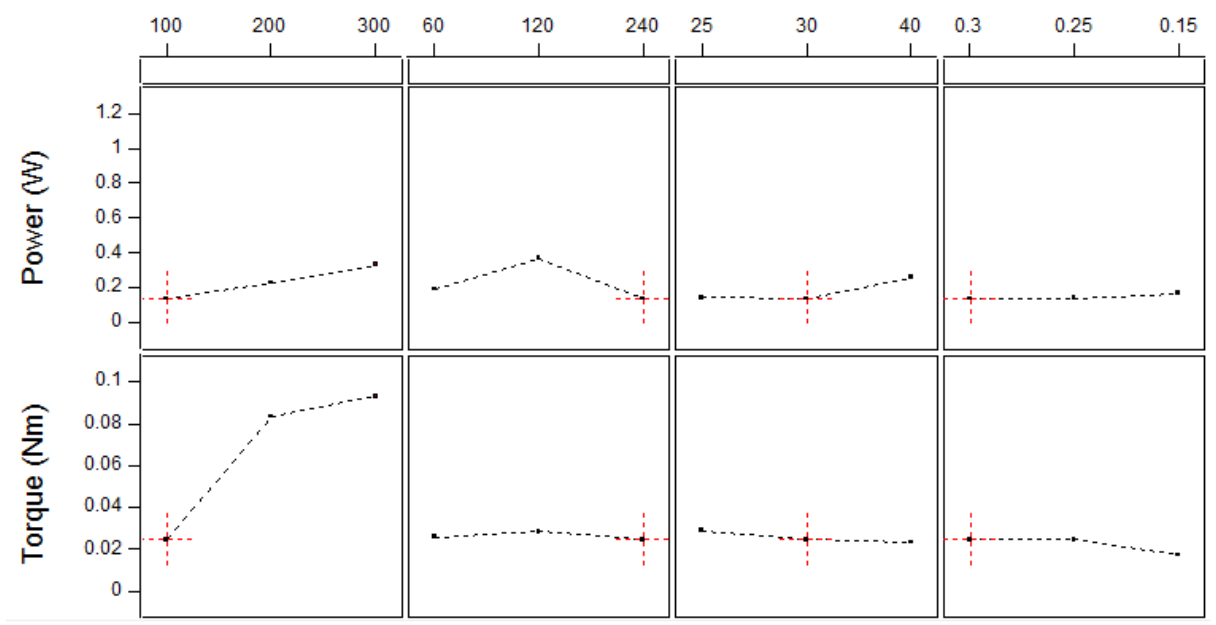

Fig. 7. Graph between Power and Torque vs. the input parameters

Table 5. Optimized levels for the factors

\begin{tabular}{|c|c|c|c|c|c|c|c|c|c|}
\hline $\begin{array}{l}\text { Roller } \\
\text { diameter } \\
(\mathrm{mm})\end{array}$ & $\begin{array}{l}\text { Speed } \\
(\mathrm{rpm})\end{array}$ & $\begin{array}{l}\text { Reduction } \\
\%\end{array}$ & $\begin{array}{l}\text { Coefficient } \\
\text { of Friction }\end{array}$ & $\begin{array}{l}\text { Effective } \\
\text { Stress } \\
\text { (N/mm2) }\end{array}$ & $\begin{array}{l}\text { Spread } \\
(\mathrm{mm})\end{array}$ & $\begin{array}{l}\text { Hardness } \\
\text { (BHN) }\end{array}$ & Strain Rate & $\begin{array}{l}\text { Power,(Wa } \\
\text { tt) }\end{array}$ & $\begin{array}{l}\text { Torque(N- } \\
\text { m) }\end{array}$ \\
\hline 100 & 240 & 30 & 0.3 & 34.65 & 5.18 & $\begin{array}{r}233.5 \\
1\end{array}$ & 99.16 & 0.140 & 0.025 \\
\hline
\end{tabular}

\section{Confirmation Simulation}

A confirmation simulation is needed to determine the optimum conditions and to compare the results with the expected conditions [15]. Using the optimal data, confirmation simulation was done to validate the generated solution. For the roller diameter of $100 \mathrm{~mm}$, the speed of $240 \mathrm{rpm}$, reduction of $30 \%$, and coefficient of friction of 0.3 , the result obtained were as given in the table. These are the condition for getting the effective values of the rolling parameters. The parameters like effective stress, spread, power, and torque are lower values where as the strain rate and hardness are at optimal levels. The optimal value obtained by simulation and prediction are similar with some slight deviation. The 
deviations are lesser than 5\% in most of the cases except for the hardness. The hardness and strain rate have more deviations compared with others. This is because it is not possible to predict the exact hardness and strain rates through simulation as it depends on many factors like microstructures and work hardening. These two parameters should be isolated and using other mathematical model it can be simulated to get the actual value to the experiment.

Table 6. Comparison of Simulated and Predicted value

\begin{tabular}{|l|l|l|l|l|l|l|l|l|l|l|l|}
\hline & $\begin{array}{l}\text { Roller } \\
\text { diameter } \\
(\mathbf{m m})\end{array}$ & $\begin{array}{l}\text { Speed } \\
(\mathbf{r p m})\end{array}$ & $\begin{array}{l}\text { Reduction } \\
\%\end{array}$ & $\begin{array}{l}\text { Coefficient } \\
\text { of Friction }\end{array}$ & $\begin{array}{l}\text { Effective } \\
\text { Stress } \\
\left(\mathbf{N} / m^{2}\right)\end{array}$ & $\begin{array}{l}\text { Spread } \\
(\mathbf{m m})\end{array}$ & $\begin{array}{l}\text { Hardness } \\
(\mathbf{B H N})\end{array}$ & $\begin{array}{l}\text { Strain } \\
\text { Rate }\end{array}$ & $\begin{array}{l}\text { Power,(W } \\
\text { att) }\end{array}$ & $\begin{array}{l}\text { Torque(N- } \\
\text { m) }\end{array}$ \\
\hline $\begin{array}{l}\text { Simulation } \\
\text { value }\end{array}$ & 100 & 240 & 30 & 0.3 & 35.9 & 5.5 & 217.2 & 110 & 0.15 & 0.029 \\
\hline $\begin{array}{l}\text { Predicted } \\
\text { value }\end{array}$ & 100 & 240 & 30 & 0.3 & 34.65 & 5.182 & 233.5 & 99.2 & 0.140 & 0.025 \\
\hline
\end{tabular}

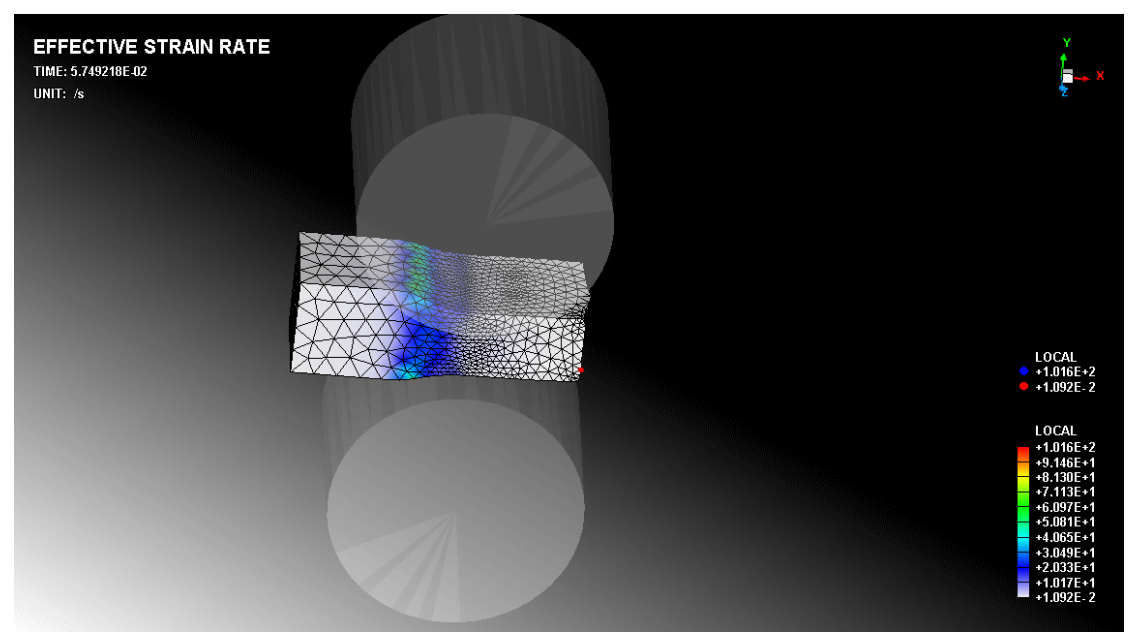

Fig. 5. Rolling trial for optimal value

\section{Conclusions}

Using the Taguchi method, the process parameters that affect the rolling process are studied. The variables such as roller diameter, speed, reduction and coefficient of friction affect the output parameters such as effective stress, strain rate, hardness, power torque and spread. The following are the observation made

-The optimum rolling conditions are said to be at roller diameter of $100 \mathrm{~mm}$, the speed of $240 \mathrm{rpm}$, reduction of $30 \%$ and coefficient of friction of 0.3 .

-Effective stress increases with increase in roller diameter and speed.

-Spread increases linearly with increase in reduction.

-Strain rate increases significantly with increase in roller diameter.

- Friction has no significant influence on the power.

- Speed and seduction cause fewer variations in the torque value. 


\section{Acknowledgment}

Authors would like to acknowledge for providing research grants from TEQIP-II, World Bank grants, Govt. of India and DHIO, Research and Engineering Pvt. Ltd. Bangalore for their research support.

\section{References}

[1] R. Jain, K. Kumari, R. K. Kesharwani, S. Kumar, S. K. Pal, and S. B. Singh, Modern Manufacturing Engineering. 2015.

[2] G. Banaszek, S. Berski, H. Dyja, and A. Kawałek, "Theoretical modelling of metallurgical defect closing-up processes during forming a forging," J. Iron Steel Res. Int., vol. 20, no. 9, pp. 111-116, 2013.

[3] T. Kroib, U. Engel, and M. Merklein, "Comprehensive approach for process modeling and optimization in cold forging considering interactions between process, tool and press," J. Mater. Process. Technol., vol. 213, no. 7, pp. 11181127, 2013.

[4] T. Gangopadhyay, D. K. Pratihar, and I. Basak, "Expert system to predict forging load and axial stress," Appl. Soft Comput. J., vol. 11, no. 1, pp. 744-753, 2011.

[5] M. R. Doddamani and M. Uday, "Simulation of Closed die forging for Stud Bolt and Castle Nut using AFDEX," vol. 1, no. 3, pp. 16-22, 2012.

[6] M. Sanjari, P. Saidi, A. Karimi Taheri, and M. Hossein-Zadeh, "Determination of strain field and heterogeneity in radial forging of tube using finite element method and microhardness test," Mater. Des., vol. 38, pp. 147-153, Jun. 2012.

[7] T. Sheppard and D. X, "A new spread formula for hot flat rolling of aluminium," Model. Simul. Mater. Sci. Eng., vol. 10, pp. 597-610, 2002.

[8] A. Pesin, A. Korchunov, and D. Pustovoytov, "Finite Element Simulation of Shear Strain in various Asymmetic cold Rolling Processes," Издается с марта 2003 года, pp. 32-40, 2014.

[9] M. Bagheripoor and H. Bisadi, "Effects of rolling parameters on temperature distribution in the hot rolling of aluminum strips," Appl. Therm. Eng., vol. 31, no. 10, pp. 1556-1565, 2011.

[10] E. I. Poliak and J. J. Jonas, "Critical Strain for Dynamic Recrystallization in Variable Strain Rate Hot Deformation," ISIJ Int., vol. 43, no. 5, pp. 692-700, 2003.

[11] A. R. Shahani, S. Setayeshi, S. A. Nodamaie, M. A. Asadi, and S. Rezaie, "Prediction of influence parameters on the hot rolling process using finite element method and neural network," J. Mater. Process. Technol., vol. 209, no. 4, pp. 1920-1935, 2009.

[12] H. Pirgazi, A. Akbarzadeh, R. Petrov, and L. Kestens, "Microstructure evolution and mechanical properties of AA1100 aluminum sheet processed by accumulative roll bonding," Mater. Sci. Eng. A, vol. 497, no. 1-2, pp. 132-138, 2008.

[13] Y. S. Tarang, "Optimization of the submerged arc welding process," Mater. Manuf. Process, vol. 13, no. 3, pp. 455-467, 1998.

[14] P. M. George, B. K. Raghunath, L. M. Manocha, and A. M. Warrier, "EDM machining of carbon-carbon composite - A Taguchi approach," J. Mater. Process. Technol., vol. 145, no. 1, pp. 66-71, 2004.

[15] Ö. Savaş and R. Kayikci, "Application of Taguchi's methods to investigate some factors affecting microporosity formation in A360 aluminum alloy casting," Mater. Des., vol. 28, no. 7, pp. 2224-2228, 2007. 